\title{
Psicofisiologia da dor: uma revisão bibliográfica
}

DOI: 10.3395/reciis.v2i1.133pt

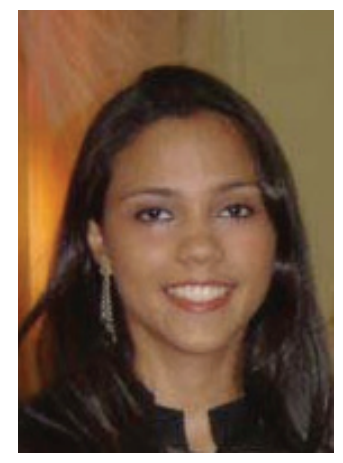

Aline Olineira Vitor

Instituto Superior de Ciências Biomédicas, Universidade Estadual do Ceará, Fortaleza, Brasil

alineovitor@yahoo.com.br

\section{Paula M. Soares}

Rede Nordeste de Biotecnologia, Universidade Estadual do Ceará, Fortaleza, Brasil mathiaz77@yahoo.com.br

\section{Maria E. de Sousa Rodrigues}

Instituto Superior de Ciências Biomédicas, Universidade Estadual do Ceará, Fortaleza, Brasil

izabetel@yahoo.com.br

\section{Raquel C. de Sousa Lima}

Instituto Superior de Ciências Biomédicas, Universidade Estadual do Ceará, Fortaleza, Brasil

raquelnut@gmail.com

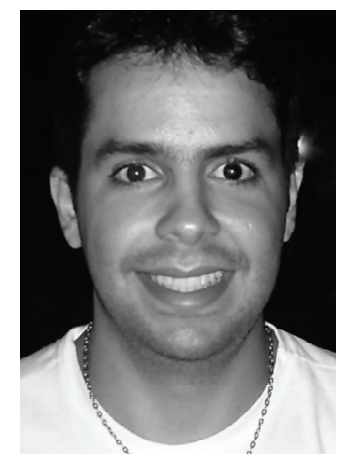

Edson Lopes da

\section{Ponte}

Instituto Superior de Ciências Biomédicas- Universidade Estadual do Ceará, Fortaleza, Brasil edson_uece@yahoo.com.br

\section{Krihsnamurti de M. Carvalho} Instituto Superior de Ciências Biomédicas, Universidade Estadual do Ceará, Fortaleza, Brasil carvalhokris@yahoo.com.br

\section{Manoel Cláudio A. Patrocinio}

Faculdade de Medicina Christus.

Fortaleza, Brasil

claudiopatrocinio@yahoo.com

\section{Silvânia M. M. Vasconcelos}

Instituto Superior de Ciências Biomédicas, Universidade Estadual do Ceará, Fortaleza, Brasil silvania@pesquisador.cnpq.br

\section{Resumo}

A dor é definida pela Associação Internacional para o Estudo da Dor como sendo "uma experiência emocional e sensorial desagradável associada a uma lesão tecidual real ou potencial ou descrita em termos de tal lesão". O aspecto sensorial da dor está associado ao processo de transmissão do impulso doloroso o qual é denominado de nocicepção. Já o aspecto emocional, por sua vez, está relacionado com as respostas comportamentais à dor. De acordo com a duração, a dor pode ser classificada em aguda ou crônica. É através da dor que se pode perceber um sinal de alerta para um perigo iminente, estando assim relacionada com a proteção do organismo, exibindo os limites que não podem ser transgredidos. Além de induzir anormalidades físicas, a dor pode alterar o equilíbrio psicológico do indivíduo. O objetivo deste trabalho é mostrar uma revisão bibliográfica sobre a psicofisiologia da dor, visando esclarecer as suas vias de ação e sua relação com alterações comportamentais. O tratamento da dor é feito baseando-se na sua etiologia e fisiopatologia e suas repercussões com o uso de fármacos analgésicos e adjuvantes. Além disso, medidas não farmacológicas, como recursos de medicina física e de reabilitação, somados aos procedimentos psicoterápicos, devem ser incluídas no tratamento.

\section{Palavras-chave}

Dor, nocicepção, psicofisiologia, percepção 


\section{Introdução}

A dor é definida pela Associação Internacional para o Estudo da Dor (IASP) como sendo "uma experiência emocional e sensorial desagradável associada com uma lesão tecidual real ou potencial ou descrita em termos de tal lesão". A sensação dolorosa tem papel fisiológico e funciona como um sinal de alerta para percepção de algo que está ameaçando a integridade física do organismo (CHAPMAN et al., 1999). Neste sentido, a dor é um sintoma clinicamente importante para a detecção e avaliação de doenças, bem como, para induzir um comportamento de precaução e, conseqüentemente, limitar os possíveis danos (MILLAN, 1999; WOOLF, 2000; ALMEIDA et al., 2004).

Já está bem estabelecido que a dor é uma experiência complexa e que não envolve apenas a transdução de estímulo nocivo ambiental, mas também o processamento cognitivo e emocional pelo encéfalo (CHAPMAN et al., 1999; JULIUS et al., 2001; ALMEIDA et al., 2004).

O fenômeno doloroso, portanto, possui dois componentes: um que discrimina o estímulo doloroso em relação ao tempo, espaço e intensidade, chamado de perceptivo-discriminativo (componente sensorial); e outro que atribui emoções à experiência dolorosa, sendo responsável pelas respostas comportamentais à dor. Este é caracterizado por comportamentos defensivos, como a retirada reflexa dos membros ou comportamento fuga/ luta, denominado de componente aversivo-cognitivomotivacional (componente motivacional) (MELZACK, 1975; ALMEIDA et al., 2004).

O componente sensorial diz respeito ao mecanismo pelo qual o impulso doloroso, gerado pela injúria tecidual real ou potencial, chega ao sistema nervoso central (SNC). Tal mecanismo é chamado de nocicepção (MERSKEY et al., 1979). Já o componente motivacional está relacionado às características do indivíduo no que concerne ao humor, ao significado simbólico dado ao fenômeno sensitivo e aos aspectos culturais e afetivos (TEIXEIRA et al., 2001).

A dor é importante, pois é através dela que se pode perceber um sinal de alerta para um perigo iminente, estando assim relacionada com a proteção do organismo, exibindo os limites que não podem ser transgredidos (DIAS, 2007).

Apesar das sensações dolorosas serem um aviso do qual o organismo se utiliza para sinalizar um processo de agressão, a problemática da dor acompanha a humanidade na medida em que interfere na homeostasia do indivíduo e da sua relação com os outros (PIRES, 2007).

Atualmente, pesquisas são realizadas no intuito de elucidar os mecanismos fisiológicos e emocionais da dor, visando à descoberta de novos fármacos que possam reduzir ou até eliminar o processo doloroso.

O objetivo deste trabalho é mostrar uma revisão bibliográfica sobre a psicofisiologia da dor, visando esclarecer as suas vias de ação e sua relação com alterações comportamentais. Para isso, o artigo foi construído com consultas a diversos trabalhos que foram obtidos em diferentes bancos de dados: Pubmed, Sciencedirect, Medline, Lillacs, Scielo e Portal da Capes. Os termos de busca utilizados foram: dor, fisiologia da dor, psicofisiologia da dor, mecanismos da dor, entre outros, dando preferência, quando necessário, aos artigos mais recentes. Foram utilizados ainda alguns livros da área de fisiologia e farmacologia para definições mais generalizadas.

\section{Fisiologia da Dor}

\section{Tipos de dor}

Segundo OLIVEIRA (1979), dor é um aviso de alarme que o SNC utiliza para sinalizar um processo de agressão ao organismo com risco para a sua integridade física. Este alarme desencadeia um conjunto de reações de adaptação, de ordem psicológica, autonômica e motora, visando afastar o organismo da causa da agressão, preservando-o.

A dor caracteriza-se por uma resposta orgânica protetora, pois alerta o indivíduo para uma lesão iminente ou real dos tecidos, induzindo ao surgimento de respostas reflexas e comportamentais coordenadas com o intuito de manter o dano tecidual o mais controlado possível (WOOLF et al., 1999). Essa dor é classificada como aguda (TEIXEIRA et al., 2001). No entanto, quando a dor passa a se repetir ou sustentar-se por período prolongado, deixa de apresentar vantagens biológicas e passa a causar sofrimento, sendo classificada como dor crônica a qual é gerada por impulsos de pequena magnitude produzidos por atividade neural anormal (MELZACK et al., 1999).

A dor crônica pode estar associada com a continuação da patologia ou persistir após a recuperação da doença ou lesão. Se a dor crônica for devido à doença orgânica, ela é efetivamente curada ao se tratar a desordem de base. Geralmente não é bem localizada e tende a ser maciça, dolorida, contínua ou recorrente e é dividida em nociceptiva, neuropática e psicogênica (MERSKEY et al., 1994; SMITH et al., 1986; FÜRST, 1999).

A dor nociceptiva consiste na estimulação persistente de nociceptores, seja térmico, químico ou mecânico. Nesta dor ocorre ativação contínua das vias centrais da dor e pode ser identificada em pessoas com câncer, Herpes zoster, entre outras (MILLAN, 1999).

Já a dor neuropática, segundo a IASP, é definida como uma dor causada ou iniciada por uma lesão primária ou por disfunção do SNC e/ou Periférico (SNP). Esta desordem pode ser provocada por compressão, transecção, infiltração, isquemia, injúria metabólica de corpos celulares de neurônios ou uma combinação desses fatores (GALLUZZI, 2007). Dor do membro fantasma e doenças como Diabetes melittus e Parkinson são as principais causas da dor neuropática (BOWSHER, 1999).

A dor psicogênica, por sua vez, está relacionada à prevalência de fatores psicológicos na gênese da sensação dolorosa. Esse tipo de dor pode ser observado em distúrbios psicológicos como na depressão e na ansiedade generalizada (FURST, 1999; MERSKEY, 1986). 


\section{Percepção da dor}

A percepção da dor ocorre em dois estágios distintos. O primeiro, denominado nocicepção, refere-se à transdução do estímulo doloroso ao SNC por receptores especializados, os nociceptores (FURST, 1999). O segundo estágio é referente ao processamento elaborado dessa informação nociceptiva, levando à percepção consciente da dor (BALDO, 1999).

O processo doloroso tem início nos nociceptores, os quais são receptores morfologicamente diferenciados e estão presentes nas terminações livres das fibras nervosas aferentes (FURST, 1999). Eles são sensiblizados quando o estímulo é potencialmente perigoso, ou seja, excede uma determinada faixa considerada fisiológica (estímulo inócuo) (BURGESS et al., 1967; MILLAN, 1999).

Os nociceptores, localizados na porção distal dos neurônios aferentes sensoriais (neurônios de primeira ordem), estão amplamente distribuídos na pele, vasos, músculos, articulações e vísceras (JULIUS et al., 2001). Dividem-se em três classes: os mecanoceptores, sensíveis a estímulos mecânicos intensos; os termoceptores, sensíveis a estímulos térmicos (acima de $45^{\circ} \mathrm{C}$ ) e os nociceptores polimodais, sensíveis tanto a estímulos mecânicos e térmicos quanto químicos (TEIXEIRA et al., 1994; BESSON, 1999). Esses receptores, como característica fundamental, não exibem acomodação e, além disso, apresentam facilitação e aumento da sensibilidade quando estimulados continuamente (CHEN et al., 1996; LIEBESKIND, 1976).

A estimulação dos nociceptores, que pode ocorrer devido à mudança de temperatura (estímulo nocivo térmico), diferença osmótica ou distensão do tecido (estímulo nocivo mecânico), hipóxia ou lesão tecidual seguida de inflamação (estímulo nocivo químico), promove uma liberação local de mediadores químicos, tais como bradicinina, prótons, histamina, serotonina, metabólitos do ácido araquidônico, ATP, adenosina, citocinas, aminoácidos excitatórios, óxido nítrico, substância $\mathrm{P}$, neurotrofinas, bombesina, opióides, somatostatina, acetilcolina, entre outros. Estes mediadores interagem com nociceptores específicos conduzindo à propagação do sinal nociceptivo por alteração na permeabilidade da membrana da fibra nervosa gerando o potencial de ação (JULIUS et al., 2001; GRIFFIS et al., 2006).

Há ainda os chamados nociceptores silenciosos (silent ou sleeping) os quais existem em pequena proporção nas fibras aferentes primárias e não respondem normalmente a estímulos. No entanto, quando estimulados por mediadores inflamatórios ou após a administração de agentes flogísticos (pró-inflamatórios), estes nociceptores apresentam atividade espontânea ou tornam-se sensibilizados e respondem a estímulos sensoriais (JULIUS et al., 2001).

Os nociceptores transmitem as informações dolorosas para a medula espinhal através das fibras sensoriais aferentes que podem ser de três tipos: fibras $A \beta$, que são fibras mielinizadas com diâmetro maior que $10 \mu \mathrm{m}$, velocidade de condução de $30-100 \mathrm{~m} / \mathrm{s}$ e que respondem à estimulação tátil; fibras $\mathrm{A} \delta$, as quais são mielinizadas de diâmetro médio de 2-6 $\mu \mathrm{m}$, com velocidade de condução de $12-30 \mathrm{~m} / \mathrm{s}$ e são responsáveis pela condução rápida do estímulo doloroso; e fibras C, que são amielínicas e de diâmetro pequeno variando de $0,4-1,2 \mu \mathrm{m}$, velocidade de condução de $0,5-2 \mathrm{~m} / \mathrm{s}$, são responsáveis pela condução lenta do impulso doloroso. As fibras C constituem a maior parte das fibras sensoriais (FURST, 1999; GRUBB, 1998; SHELLEY et al., 1994).

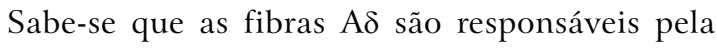
condução da "primeira dor" que se caracteriza por ser rápida, aguda e pontual, enquanto as fibras $\mathrm{C}$ transmitem a "segunda dor", sendo esta atrasada, difusa e fraca (JULIUS et al., 2001).

Os nociceptores periféricos, situados nas terminações periféricas de neurônios primários, apresentam seus corpos celulares constituindo os gânglios das raízes dorsais. Eles transmitem a informação nociceptiva aos neurônios do corno dorsal da medula espinhal. Os principais neurotransmissores responsáveis pela transmissão do impulso nervoso das fibras aferentes primárias para os neurônios do corno dorsal da medula são a substância P e o glutamato (CALNE et al., 1996; CODERRE et al., 1992). Este processo também depende de canais de cálcio e sódio, sendo os primeiros os principais reguladores da liberação de neurotransmissores (HILL, 2001).

O corno dorsal, por sua vez, apresenta-se dividido em seis lâminas de acordo com as características dos seus neurônios, existindo uma correspondência anátomo-funcional. Os neurônios nociceptivos estão localizados nas lâminas I, II e V (ALMEIDA et al., 2004).

Após a interação direta ou indireta com neurônios aferentes primários no corno dorsal, os axônios de neurônios de segunda ordem formam tratos aferentes que transmitem os impulsos nociceptivos para estruturas do tronco cerebral e diencéfalo, incluindo tálamo, substância cinzenta periaquedutal, formação reticular da medula, complexo amigdalóide, hipotálamo, entre outras (ALMEIDA et al., 2004).

O envio da informação dolorosa para os centros superiores ocorre por meio das vias de projeção da dor ou trato anterolateral da coluna. As principais vias de condução da dor no SNC são o trato espinotalâmico, o trato espinorreticular e o trato espinomesencefálico (CAILLIET, 1999; MILLAN, 1999).

O trato espinorreticuular, também conhecido como via de condução lenta, é filogeneticamente mais antigo e cursa medialmente no tronco cerebral. Está ligado ao Sistema Reticular Ativador Ascendente (SARA) e a Substância Cinzenta Periaquedutal Ventral (SCPV) e envia projeções difusas para o tálamo, córtex e estruturas do sistema límbico. Já o trato espinotalâmico, ou vias de condução rápida, é filogeneticamente mais novo e cursa lateralmente no tronco cerebral. Envia projeções para o tálamo ventrobasal e daí para o córtex sensorial (RUSSO et al., 1998).

Outra via importante é a representada pelo trato espinomesencefálico, que termina em algumas regiões do mesencéfalo, onde se incluem a formação reticular mesencefálica e a substância cinzenta periaquedutal. Essa última região mantém conexões recíprocas com o 
sistema límbico por intermédio do hipotálamo (BALDO, 1999).

O trato anterolateral é cruzado no homem, mas possui um componente ipsilateral pequeno, porém significativo, que pode explicar o retorno da dor em pacientes que sofreram secção desse trato, chamada de dor fantasma. As vias de projeção da dor possuem grandes divergências de terminações no tronco cerebral dando suporte neural para a ativação comportamental e o alerta induzido pelo estímulo doloroso. Muitas das fibras anterolaterais ativadas pela dor terminam no teto mesencefálico (BASBAUM et al., 2002).

Muitos neurotransmissores e moduladores envolvidos na transmissão do sinal nociceptivo da medula para os centros superiores estão sendo descobertos. Contudo, estudos eletrofisiólogicos sugerem que o glutamato e outros aminoácidos excitatórios, que agem via receptores ionotrópicos e receptores metabotrópicos para glutamato, estão envolvidos na transmissão da informação nociceptiva do trato espinotalâmico para o tálamo, e do trato espinomesencefálico para a SCPV (AZKUE et al., 1997; ERICSSON et al., 1995; JENSEN et al., 1992; SALT et al., 1996).

O tálamo desempenha um papel fundamental na integração do impulso doloroso. A partir do tálamo, neurônios de terceira ordem transmitem impulsos para o córtex cerebral, onde ocorre o processamento que resulta em consciência da dor (FÜRST, 1999).

As vias descendentes, que partem do mesencéfalo pelo bulbo ventromedial rostral e chegam ao corno dorsal da medula espinhal, dirigem-se em sentido diametralmente oposto ao da via sensitiva ascendente. Elas exercem um efeito inibitório e modulador sobre estruturas distais, muito particularmente sobre o cordão posterior da medula, onde o balanço entre aferências nociceptivas e não-nociceptivas pode controlar a transmissão de informação dolorosa para centros superiores (MELZACK et al., 1965; GUTSTEIN et al., 1998).

\section{Teoria da Comporta}

A teoria mais aceita para explicar a regulação da dor é a teoria da comporta. Foi proposta por Ronald MELZACK e Patrick WALL em 1965. Constitui-se em um modelo de percepção da dor no qual há uma regulação da passagem dos impulsos das fibras aferentes periféricas para o tálamo através dos neurônios de transmissão no corno dorsal. Ela funciona como uma estação regulatória para a transmissão da dor. Assim, a percepção da dor se dá pelo somatório da estimulação sensorial e um intenso controle central.

As fibras aferentes nociceptivas transmitem o impulso doloroso para o tálamo através de células transmissoras da dor localizadas no corno dorsal na medula espinhal, constituindo a via de transmissão da dor, a qual é controlada pelos neurônios da substância gelatinosa (SG). Neurônios inibitórios descendentes ou influxo aferente não-nociceptivo ativam os neurônios da SG os quais, por sua vez, inibem as células transmissoras da dor dificultando a passagem do impulso doloroso para os centros superiores. Já a estimulação das fibras C, inibe os neurônios inibitórios da SG permitindo a passagem do impulso doloroso para o tálamo, constituindo-se então o processo de regulação da passagem do impulso doloroso para os centros superiores (YAKSH et al., 1994).

A teoria da comporta não aborda somente o aspecto sensorial da dor, mas também as variáveis psicológicas e sua influência na sensação dolorosa. Isso ocorre por meio de uma avaliação cognitiva e por informações de experiências anteriores que estão armazenadas em regiões corticais superiores ligadas ao componente motivacional. Alterações neste componente, principalmente na dor crônica, podem modificar as reações à dor mesmo não havendo mudanças no seu componente sensorial (BROTON et al., 1982).

\section{Controle central da Dor}

Sabe-se que os impulsos dolorosos estão sujeitos a influências modulatórias centrais e que, em situações de estresse físico ou de grande concentração, os estímulos dolorosos são tolerados. Foi sugerida, então, a existência de um sistema fisiológico de controle central da dor. Esse sistema pode ser ativado também por estímulos como doenças, comportamento cognitivo ou até mesmo pela própria dor (URBAN et al., 1999).

O processo analgésico ocorre pela estimulação de vários locais como a SCPV, locus coeruleus e o Bulbo Raquidiano Ventromedial Rostral (BRVMR). Projeções diretas conectam o córtex pré-frontal e insular, o hipotálamo, a amígdala e o tronco cerebral à SCPV. Esta se liga ao BRVMR o qual, por sua vez, projeta-se para o corno dorsal da medula. O BRVMR é a maior fonte de neurônios do tronco cerebral para o corno dorsal, principalmente para as lâminas I, II e V (FIELDS et al., 1999; URBAN et al., 1999). Deste modo, a estimulação da SCPV provoca excitação dos neurônios do BRVMR que, por sua vez, liberam neurotransmissores, como serotonina e encefalina, os quais vão inibir as respostas nociceptivas dos neurônios do corno dorsal, provocando assim uma diminuição das respostas à dor (BASBAUM et al., 2000).

Existe também a via noradrenérgica proveniente do locus coeruleus, que possui como principal antagonista a noradrenalina (FRITSCHY et al.,1987; CLARK et al., 1991). Esta exerce um efeito inibitório sobre a transmissão da dor no corno dorsal (BELCHER et al., 1978).

A administração intratecal de noradrenalina causa antinocicepção comprovando sua participação no controle da dor (YAKSH et al., 1979; REDDY et al., 1980). Além disso, antagonistas da noradrenalina reduzem a antinocicepção produzida pela estimulação da medula supraespinhal (BARBARO et al.,1985; JONES et al., 1986).

\section{Receptores e ligantes da Dor}

Os principais receptores da dor são os opióides, serotoninérgicos, noradrenérgicos e vanilóides.

Os receptores opióides possuem uma distribuição seletiva. Estão mais presentes no sistema límbico e 
na SCPV, podendo também ser encontrado no SNP (HARLAN et al., 2002). Os receptores opióides são observados em áreas correlacionadas com a percepção da dor (lâminas I, II e V), a modulação do comportamento afetivo (amígdala, hipocampo, locus coeruleus e córtex) e a regulação do sistema nervoso autônomo e funções neurodegenerativas (bulbo e hipotálamo) (ARVIDSSON et al., 1995a,b).

Estudos demonstram que o efeito analgésico dos opióides é devido à sua propriedade em inibir, de maneira direta, a transmissão ascendente das informações nociceptivas provenientes do corno dorsal da medula espinhal e ativar os circuitos de controle da dor que descem do mesencéfalo pelo bulbo ventromedial rostral e chegam ao corno dorsal da medula espinhal. Os peptídeos opióides e seus receptores são encontrados em todos esses circuitos descendentes da dor (GUTSTEIN et al., 1998).

Os tipos de receptores opióides são $\mu$ (mi), $\kappa$ (kappa) e $\delta$ (delta). Eles diferem entre si por diferentes afinidades aos ligantes opióides endógenos e também às drogas opióides exógenas. Os principais ligantes opióides são: encefalina, seletiva para receptores tipo delta; dinorfina, seletiva para receptores tipo kappa; e endorfina a qual possui alta afinidade para receptores tipo delta e mi e baixa afinidade para receptores tipo kappa (LORD et al., 1977). Todos eles são acoplados a proteína G e inibem a adenilato ciclase, reduzindo assim o conteúdo intracelular de monofosfato cíclico de adenosina (AMPc) (DHAWAN et al., 1996).

As encefalinas, por exemplo, que estão presentes nos interneurônios da SG da medula espinhal posterior, apresentam efeitos antinociceptivos que parecem ser ativados pelas ações pré e pós-sinápticas para inibir a liberação de substância P e diminuir a atividade das células que se projetam da medula espinhal para os centros mais altos do SNC (HOFFMAN et al., 2003).

Em relação aos receptores serotoninérgicos, estes são metabotrópicos do tipo 5-HT $1 \mathrm{~A}$ e possuem como principal ligante a serotonina (ou 5-hidroxitriptamina - 5-HT) que estão presentes principalmente no núcleo magno da rafe (HOYER et al., 1994). Em particular, esse núcleo possui um papel crucial na integração da nocicepção e informações afetivas através de projeções descendentes para a medula espinhal e projeções ascendentes para o córtex cerebral (YAARI et al., 1985).

A serotonina está envolvida em múltiplos níveis de regulação da nocicepção. A liberação desse neurotransmissor inibe a transmissão do impulso doloroso para o SNC induzindo à analgesia. Os núcleos serotoninérgicos dorsais da rafe, sob a influência de vias encefalinérgicas, modulam a atividade do núcleo acumbbens, amígdala e habênula (YAARI et al., 1985; MICO et al., 2006).

Já os receptores vanilóides são canais de cátions não seletivos que são ativados pelo calor (temperaturas acima de $43^{\circ} \mathrm{C}$ ), baixo $\mathrm{pH}$, lipídios endógenos, como a anandamida e produtos da ação de lipoxigenases. Eles encontram-se distribuídos em neurônios aferentes primários, gânglios da raiz dorsal e em todo o cérebro (CATERINA et al., 1997).
Evidências recentes mostram que os receptores vanilóides, estimulados por endocanabinóides ou pela capsaicina na SCPV, induzem analgesia. Este efeito análgesico está associado ao aumento da liberação de glutamato e ativação de células da medula ventromedial rostral. A ativação da via nociceptiva descendente por estimulação desse receptor na SCPV pode ser uma nova estratégia para produzir analgesia (PALAZZO et al., 2008; MAIONE et al., 2006; JIA et al., 2005).

\section{Aspectos motivacionais da Dor}

A dor possui um aspecto emocional que contribui para uma potencialização dependendo da experiência vivenciada pelo indivíduo (MELZACK et al., 1999). Em determinadas situações sua intensidade e duração não mantêm uma relação de proporcionalidade com o estímulo agressor (LOESER et al., 1999; MILLAN, 1999), exibindo a participação do componente emocional na sensação dolorosa.

Os estímulos sensoriais da dor estão ligados a comportamentos defensivos. Já se sabe que, anatomicamente, existe superposição de substratos neurais que estão ligados ao comportamento dor/medo no teto mesencefálico (BASBAUM et al., 2002). Existem também evidências de que o medo inibe a dor em humanos (RHUDY et al., 2004).

Bolles e Fanselow, em 1980, propuseram um modelo para explicar o comportamento medo/dor chamado de modelo perceptivo recuperativo (PDR). Ele mostra que o medo e a dor geram comportamentos distintos.

Após uma lesão dolorosa dois comportamentos podem ser ativados: o comportamento recuperativo, responsável pelo restabelecimento do indivíduo, ou o comportamento defensivo, que inibe tanto o comportamento recuperativo quanto a dor e promove a percepção ambiental e a defesa (BOLLES et al., 1980). Isto é, o medo ativa mecanismos opióides endógenos que inibem o sistema motivacional da dor, pois a expressão deste sistema pode competir e até mesmo ser incompatível com o comportamento defensivo (RHUDY et al., 2004).

O modelo PDR pode ser divido em três fases: perceptiva, defensiva e recuperativa (BOLLES et al., 1980). A fase perceptiva é uma fase breve onde ocorre à detecção do estímulo e sua aprendizagem a qual é condicionante, ou seja, um estímulo que serve como sinal de memória daquele que gerou algum trauma poderá evocar comportamentos defensivos.

O papel dessa aprendizagem é fazer com que o estímulo condicionado induza uma expectativa do estímulo não condicionado. Se o estímulo não condicionado ocorre novamente, as suas características reais são confrontadas com as características esperadas. Qualquer discrepância entre os sinais percebidos e esperados gera correções pelo sistema de aprendizagem de forma a evitar expectativas errôneas no futuro. É a expectativa do estimulo não condicionado que gera o comportamento defensivo. Assim, na conversão da nocicepção em dor estão envolvidos fatores como experiência prévia, cognitivas, contexto 
cultural e social (BROTON et al., 1982), podendo gerar respostas diferentes à experiência dolorosa em diferentes indivíduos e em diferentes momentos (MELZACK, 1975; MELZACK et al., 1994; MELZACK et al., 1971; BOLLES et al., 1980).

A fase defensiva é o momento onde ocorre a reação ao estímulo com o aumento do medo e diminuição da dor ativando o sistema analgésico endógeno e gerando comportamento defensivo. Já na fase recuperativa, ocorre a cura da injúria com ativação do sistema motivacional da dor pelo dano tissular e inibição de qualquer outro tipo de motivação. Nesta fase prevalece o comportamento recuperativo com cuidados corporais e repouso e o indivíduo torna-se dependente e afetado (BOLLES et al., 1980).

\section{Alterações psicológicas na Dor}

A dor é subjetiva e particular, pois cada indivíduo a expressa de acordo com suas experiências baseando-se nas lesões que ocorreram desde o seu nascimento (MERSKEY et al., 1979). Observa-se então a subjetividade na interpretação do fenômeno doloroso com seu caráter emocional e sensitivo. A dor, portanto, além de induzir anormalidades físicas, altera o equilíbrio psicológico do indivíduo (TEIXEIRA, 2006).

A dor crônica pode levar a disfunções psicológicas e sociais importantes. Tais disfunções podem ser causadas pelo déficit de neurotransmissores, alterações nos receptores, transtorno dos ritmos biológicos, anormalidades neuroendócrinas, imunológicas e/ou fatores genéticos (TEIXEIRA, 2006).

Pessoas que sofrem de dores crônicas apresentam uma maior propensão à doença depressiva quando comparados com indivíduos normais (SULLIVAN et al., 1992). Cerca de 30\% a 54\% dos pacientes com dores crônicas, como cefaléia, dor facial, cervicalgia, lombalgia, dores torácicas, abdominais, pélvicas e nas extremidades, apresentam freqüentemente transtornos depressivos (BANKS et al.,1996; VON KNORRING et al., 1983) e, geralmente, necessitam de tratamento especializado (WARD, 1990).

Por outro lado, pessoas com depressão ou ansiedade estão mais vulneráveis à dor. Um considerável número de pessoas com depressão, especialmente quando acompanhada de ansiedade, apresentam queixas dolorosas (WÖRTZ, 1994). Elas freqüentemente queixam-se de dor crônica, muitas vezes em várias partes do corpo na ausência de lesões ou de justificativas para tal (MAGNI et al., 1990).

Situações como estresse, medo, ansiedade e duração da dor interferem na ativação do sistema opióide que está envolvido na modulação da analgesia (BROTON et al., 1982). Neuromoduladores da nocicepção são liberados quando a dor é intensa ou quando há estresse (TERMAN et al., 1984).

A depressão e a ansiedade interagem na percepção da dor via mecanismos inibitórios e facilitatórios (MEYER, 1985). As vias noradrenérgicas e serotoninérgicas estão envolvidas no mecanismo da ansiedade e da depressão, bem como no controle central da dor. A interação entre as unidades excitatórias e inibitórias, a condição emocional, os traços constitucionais, as experiências pregressas e presentes, a ocorrência de anormalidades orgânicas ou funcionais e as condições ambientais podem interferir na transmissão da informação nociceptiva para centros nervosos os quais participam da percepção ou das reações reflexas frente à dor. $\mathrm{O}$ estresse psicológico, por exemplo, torna a dor mais intensa ou menos tolerável (TEIXEIRA, 2006).

\section{Tratamento}

O tratamento deve se basear na etiologia e fisiopatologia da dor e nas suas repercussões (RAMAMURTHY et al., 1993), envolvendo assim a eliminação do fator causal com o uso de fármacos analgésicos e adjuvantes. Substâncias capazes de diminuir a condição inflamatória podem também ser empregadas no tratamento contra a dor. $\mathrm{Na}$ verdade, a grande maioria dos fármacos presentes no mercado, que são utilizados para o controle da dor, possui um cunho antiinflamatório (MENDELL et al., 2003).

Também devem ser incluídas medidas não farmacológicas como os recursos de medicina física e de reabilitação somados aos procedimentos psicoterápicos (CATALANO et al., 2004). Em situações excepcionais, procedimentos anestésicos e neurocirúrgicos podem ser valiosos no alívio de determinadas algias resistentes (TEIXEIRA, 1988).

O tratamento visa reduzir a dor e o uso de medicamentos, reintegrar funcionalmente o doente e melhorar sua qualidade de vida. Em casos de dor aguda, as intervenções visam à eliminação do desconforto e recorrem fundamentalmente à remoção das causas, à farmacoterapia analgésica e aos procedimentos simples de medicina física e de medicina comportamental (CANDELETTI et al., 1985).

No tratamento de dor crônica, ocorre o emprego de medidas sintomáticas, especialmente no uso de medicamentos adjuvantes, fisioterapia, psicoterapia e intervenções de reintegração social. A prescrição de medicamentos é, geralmente, a primeira atitude analgésica adotada tanto para dor aguda quanto para dor crônica (AMANO et al., 1986).

Os opióides são universalmente utilizados no tratamento da dor oncológica e dor aguda, embora alguns clínicos ainda resistam ao uso destes analgésicos principalmente pelo temor de suas complicações, como a depressão respiratória, e pela falta de conhecimento de respostas fisiológicas individuais frente a alguns aspectos farmacológicos, como a tolerância, a dependência física e psicológica (McQUAY, 1999).

Embora a dor nociceptiva em geral responda aos analgésicos opióides, a dor neuropática não costuma responder bem a esses fármacos e pode exigir doses maiores desses analgésicos. Portanto, os opiódes são mais eficientes no tratamento da dor nociceptiva do que na dor neuropática (FIELDS, 1988; COLOMBO et al., 2006). 
O uso de uma variedade de medicamentos antidepressivos está associado com a redução do quadro álgico, efeito este independente da mudança de humor e da qualidade destas drogas. Este alívio é uma conseqüência da ampla variedade de ações dos antidepressivos nos mecanismos neurorregulatórios da percepção e transmissão da dor (McCLEANE, 2008). O uso de antidepressivos tricíclicos é eficaz e auxilia no controle da dor (SINDRUP et al., 1999; O'MALLEY et al., 2000). Alguns agem inibindo a recaptação de serotonina, contudo existem drogas mais eficientes as quais inibem não apenas a recaptação de serotonina como também de noradrenalina (JANN et al., 2007).

\section{Considerações finais}

Após o levantamento realizado, verifica-se que o estudo da dor é algo extremamente complexo, pois além de apresentar seu aspecto sensorial de cunho anátomo-funcional (dependente das vias de transmissão) também possui uma relação com as vias envolvidas com o comportamento motivacional, podendo particularizar sua resposta frente a diferentes indivíduos. Isso acarreta uma dificuldade em seu tratamento, exemplificado pela utilização não exclusiva de fármacos analgésicos. Sendo assim, torna-se uma área de vasto conhecimento e futuras perspectivas no sentido de se entender melhor essas relações com o objetivo de se conhecer melhor e desenvolver novas formas de controle desse fenômeno.

\section{Referências bibliográficas}

ALMEIDA, T.F; ROIZENBLATT, S.; TUFIK, S. Afferent pain pathways: a neuroanatomical review. Brain Research, v.1000, n.1-2, p.40-56, Mar. 2004.

AMANO, N.; HU, J.W.; SESSLE, B.J. Responses of neurons in feline trigeminal subnucleus caudalis (medullary dorsal horn) to cutaneous, intraoral and muscle afferent stimuli. Journal of Neurophysioloby, v.55, n.2, p.227243, Feb. 1986.

ARVIDSSON, U. et al. Delta-opioid receptor immunoreactivity: distribuition in brainstem and spinal cord, and relationship to biogenic amines and enkephalin. Journal of Neuroscience, v.15, n.2, p.1215-1235, Feb. 1995.

ARVIDSSON, U. et al. Distribuition and targeting of mu-opioid receptor (MORI) in brain and spinal cord. Journal of Neuroscience, v. 15, n.5, p.3328-3341, May 1995.

AZKUE, J.J. et al. Distribution of the metabotropic glutamate receptor subtype mGluR5 in rat midbrain periaqueductal grey and relationship with ascending spinofugal afferents. Neuroscience Letters, v.228, n.1, p.1-4, May 1997.

BALDO, M.V.C. Somestesia. In: AIRES, M.M. et al. Fisiologia. 2.ed. Rio de Janeiro: Ed. Guanabara Koogan, 1999.

BANKS, S.M.; KERNS, R.D. Explaining high rates of depression in chronic pain: A diathesis-stress frame- work. Psychological Bulletin, v.119, n.1, p.95-110, Jan. 1996

BARBARO, N.M.; HAMMOND, D.L.; FIELDS, H.L. Effects of intrathecally administered methysergide and yohimbine on microstimulation-produced antinociception in the rat. Brain Research, v.343, n.2, p.223-229, Sep. 1985.

BASBAUM, A.; BUSHNELL, M.C. Pain: basic mechanisms. In: GIAMBERARDINO, M. A. Pain - an updated review - International Association for the Study of Pain. Seattle: IASP Press, 2002. p.3-7.

BASBAUM, A.I.; JESSELL, T.M. The perception of pain. In: KANDEL, E.R.; SCHWARTZ, J.H.; JESSELL, T.M. Principles of Neural Science, New York: McGraw-Hill, 2000. p.472-491.

BELCHER, G.; RYALL, R.W.; SCHAFFNER, R. The differential effects of 5-hydroxytryptamine, noradrenaline and raphe interneurons in the cat. Brain Research, v.151, n.2, p.307-21, Aug. 1978.

BESSON, J.M. The neurobiology of pain. The Lancet, v.353, n.9164, p.1610-15, May 1999.

BOLLES, R.C.; FANSELOW, M.S. A percentual-defensive-recuperative model of fear and pain. Behavioral and Brain Science, v.3, n.2, p.291-323, Jun. 1980.

BOWSHER, D. The lifetime occurrence of herpes zoster and prevalence of postherpetic neuralgia: a retrospective survey in an elderly population. European Journal Pain, v.3, n.4, p.335-342, Dec. 1999.

BROTON, J.G.; ROSENFELD, J.P. Rostral trigeminal projections signal perioral facial pain. Brain Research, v.243, n.2, p.395-400, Jul. 1982.

BURGESS, P.R.; PERL, E.R. Myelinated afferent fibres responding specifically to noxious stimulation of the skin. Journal of Physiology, v.190, n.3, p.541-562, Jun. 1967.

CAILLIET, R. Dor: mecanismo e tratamento. Porto Alegre: Artmed, 1999.

CALNE, S. M. et al. Validating aquality of life rating scale for idiopathic parkinsonism: Parkinson's Impact Scale (PIMS). Parkinsonism Related Disorders, v.2, n.4, p.55-61, Apr. 1996.

CANDELETTI, S. et al. Studies on the antinociceptive effect of intrathecal salmon calcitonin. Peptides, v.6, n.3, p.273-276, 1985.

CATALANO, E.M.; HARDIN, K.N. Dores crônicas. São Paulo: Summus Editorial, 2004.

CATERINA M.J. et al. The capsaicin receptor: a heatactivated ion channel in the pain pathway. Nature, v.389, n.6653, p.816-824, Sep. 1997.

CHAPMAN, C.R.; GAVRIN, J. Suffering: the contributions of persistent pain. The Lancet, v.353, n.9171, p.2233-2237, Jun. 1999. 
CLARK, F.M.; PROUDFIT, H.K. The projection of noradrenergic neurons in the A7 catecholamine cell group to the spinal cord in the rat demonstrated by anterograde tracing combined with immunocytochemistry. Brain Research, v.547, n.2, p.279-288, May 1991.

COLOMBO, B.; ANNOVAZZI, P. O.; COMI. G. Medications for neuropathic pain: current trends. Neurological Science, v.27, n.2, p.183-9, May 2006.

CHEN, T.H. et al. Effects of caffeine on intracellular calcium release and calcium influx in a clonal - cell line Rinm5F. Life science, v.58, n.12, p.983-990, Fev. 1996.

CODERRE, T.J.; MELZACK, R. The contribution of excitatory amino acids to central sensitization and persistent nociception after formalin-induced tissue injury. Journal of Neuroscience, v.2, n.9, p.3665-3670, Sep. 1992.

DHAWAN, B.N. et al. Classification of opioid receptors. Pharmacological Review, v.48, n.4, p.567-592, Dec. 1996.

DIAS, S.Aversão biológica da dor. Com Ciência, n.87,2007. Reportagem. Disponível em: < http://www.comciencia.br/ comciencia/ ?section $=8 \&$ \&edicao $=24 \& i d=274 \&$ tipo $=0>$, Acesso em: 19 jan. 2008.

ERICSSON, A.C. et al. Evidence for glutamate as neurotransmitter in trigemino- and spinothalamic tract terminals in the nucleus submedius of cats. European Journal of Neuroscience, v.7, n.2, p.305-317, Feb. 1995.

FIELDS, H.L.; Can opiates relieve neuropathic pain?. Pain, v.35, n.3, p.365-367, Dec. 1988.

FIELDS, H.L.; BASBAUM, A.I. Central nervous system mechanisms of pain modulation. In: WALL, P. D.; MELZACK, R. Textbook of pain, 4.ed. Edinburgh: Churchill Livingstone, 1999. p.309-329.

FRITSCHY, J.M. et al. Distribution of locus coeruleus axons in the rat spinal cord: a combined anterograde transport and immunohistochemical study. Brain Research, v.437, n.1, p.176-180, Dec. 1987.

FÜRST, S. Transmitters involvednin antinociception in the spinal cord. Brain Research Bulletin, v.48, n.2, p.129-141, Jan. 1999.

GALLUZZI, K.E. Managing neuropathic pain. JAOA, v.107, n.10, s.6, p.39-48, Nov. 2007.

GRIFFIS, C.A.; COMPTON, P.; DOERING, L. The effect of pain on leucocyte cellular adhesion molecules. Biological Research Nursing, v.7, n.4, p.297-312, Apr. 2006.

GRUBB, B.D. Peripheral and central mechanism of pain. British Journal of Anaesthesia, v.81, n.1, p.811, Jul. 1998

GUTSTEIN, H.B. et al. Mu and Kappa receptors in periaqueductal gray and rostral vetromedial medulla. Neuroreport, v.9, n.8, p.1777-81, Jun. 1998.
HARLAN, E.S.; ELIZABETH, A.L. Comparison of the peripheral and central effects of the opioid agonists loperamide and morphine in the formalin test in rats. Neuropharmacology, v.4, n.2, p.253-261, Feb. 2002.

HOFFMAN, B.B.; TAYLOR, P. Neurotransmissão: Os sistemas nervosos autônomo e motor somático. In: HARDMAN, J.G.; LIMBIRD, L.E.; GILMAN, A.G. Goodman \& Gilman: As bases farmacológicas da terapêutica. Rio de Janeiro: McGraw-Hill, p.89-1 17, 2003.

HOYER, D. et al. International Union of Pharmacology classification of receptors for 5-hydroxytryptamine (Serotonin). Pharmacological Review, v.46, n.2, p.157203, Jun. 1994.

HILL, R.G. Molecular basis for the perception of pain. Neuroscientist, v.7, n.4, p.282-292, Aug. 2001.

JANN, M.W.; SLADE, J.H. Antidepressant agents for the treatment of chronic pain and depression. Pharmacotherapy, v.27, n.11, p.1571-87, Nov. 2007.

JENSEN, T.S.; YAKSH, T.L. Brainstem excitatory amino acid receptors in nociception: microinjection mapping and pharmacological characterization of glutamate-sensitive sites in the brainstem associated with algogenic behavior. Neuroscience, v.46, n.3, p.535-547, Feb. 1992.

JIA, Y.; MCLEOD, R.L.; HEY, J.A. TRPVI receptor: a target for the treatment of pain, cough, airway disease and urinary incontinence. Drug News Perspectives, v.18 n.3, p.165-71, Apr. 2005.

JONES, S.L.; GEBHART, G.F. Quantitative characterization of ceruleospinal inhibition of nociceptive transmission in the rat. Journal of Neurophysiology v.56, n.5, p.1397-410. Nov. 1986.

JULIUS, D.; BASBAUM, A.I. Molecular mechanisms of nociception. Nature, v.413, n.6852, p.203-210, Sep. 2001 .

LIEBESKIND, J.C. Pain modulation by central nervous system stimulation. Advances in pain research and therapy. Nova York: Raven Press, v.1, p.445-547, 1976.

LOESER, J.D.; MELZACK, R. Pain: an overview. The Lancet, v.353, n.9164, p.1607-1609, May 1999.

LORD, J.A. et al. Endogenous opioid peptides: multiple agonists and receptors. Nature, v.267, n.561 1, p.495-99, Jun. 1977.

MAGNI, G. Chronic musculoskeletal pain and depressive symptoms in the general population. An analysis of the $1^{\text {st }}$ National Health and Nutrition Examination Survey data. Pain, v.43, n.3, p.293-307, Dec. 1990.

MAIONE, S. et al. Elevation of endocannabinoid levels in the ventrolateral periaqueductal grey through inhibition of fatty acid amide hydrolase affects descending nociceptive pathways via both cannabinoid receptor type 1 and transient receptor potential vanilloid type- 1 receptors. J Pharmacology and Experimental Therapeutics, v.316 n.3, p.969-82, Mar. 2006. 
McClEANE, G. Antidepressants as analgesics. CNS Drugs, v.22, n.2, p.139-56, 2008

MCQUAY, H. Opioids in pain management. The Lancet, v.353, p.2229-2232, n.9171, Jun. 1999.

MELZACK, R. The McGill pain questionnaire: major properties and scoring methods. Pain, v.1, n.3, p.27799, Sep. 1975.

MELZACK, R.; KATZ, J. Pain measurement in persons in pain. In: WALL, P.; MELZACK, R. Textbook of Pain. 3.ed. Edinburgh: Churchill Livingston, v.18, 1994. p.337-51.

MELZACK, R.; TORGERSON, W.S. On the language of pain. Anesthesiology, v.34 n 1, p 50-9, Jan. 1971.

MELZACK, R.; WALL, P.D. Pain mechanisms: a new theory. Science, v.150, n.699, p.971-79, Nov. 1965.

MELZACK, R.; WALL, P.D. Textbook of Pain. 4.ed. Londres: Churchill Livingstone. v.18, 1999.

MENDELL, J.R.; SAHENK, Z. Painful sensory neuropathy. New England Journal of Medicine, v.348, n.13, p.1243-1255, Mar. 2003.

MERSKEY, H. et al. Pain terms: a list with definitions and notes on usage. Recommended by IASP Subcomittee on Taxonomy. Pain, v.6, n.3, p.249, Jun. 1979.

MERSKEY, H. Classification of chronic pain: descriptions of chronic pain syndromes and definitions of pain terms. Pain, v.3, p.S1-S226, 1986.

MERSKEY, H.; BOGDUK, N. (Eds.). Classification of chronic pain: descriptions of chronic pain syndromes and definitions of pain terms. 2.ed. Seattle, Wash: IASP Press, 1994.

MEYER, R.A.; RAJA, S.N.; CAMPBELL, J.N. Coupling of action potential activity between unmyelinated fibers in the peripheral nerve of monkey. Science, v.227, n.4683, p.184-187, Jan. 1985.

MICO, J.A. et al. The role of 5-HTIA receptors in research strategy for extensive pain treatment. Current Topics in Medicinal Chemistry, v.6, n.18, p.19972003, Sep. 2006

MILLAN, M.J. The induction of pain: an integrative review. Progress in Neurobiology, v.57, n.1, p.1-164, Jan. 1999

OLIVEIRA, L.F. Dor: fisiopatologia, Revista Brasileira de Anestesiologia, v.28, n.3, p.227-288, 1979.

O’MALLEY, P.G. et al. Treatment of Fibromyalgia with antidepressants: a meta-analysis. Journal of General Internal Medicine, v. 15, n.9, p.659-66, Sep. 2000.

PALAZZO, E.; ROSSI, F.; MAIONE 2 S. Role of TRPV 1 receptors in descending modulation of pain. Molecular and Cellular Endocrinology, (Epub ahead of print) Feb. 2008

PIRES, A.F. Atividade antinociceptiva de uma lectina de sementes de Canavalia brasiliensis MART. Dissertação
(Mestrado Acadêmico em Ciências Fisiológicas) - Universidade Estadual do Ceará - UECE, 2007.

RAMAMURTHY, S.; ALANMANOU, E.; ROGERS, J.N. Decision making in pain management. 2.ed. New York: Mosby Year Book, 1993.

REDDY. S.V.; MADERDRUT, J.L.; YAKSH, T.L. Spinal cord pharmacology of adrenergic agonist-mediated antinociception. Journal Pharmacology and Experimental Therapy, v.213, n.3, p.525-33, Jun. 1980.

RHUDY, J.L.; GRIMES, J.S.; MEAGHER, M.W. Fearinduced hypoalgesia in humans: effects on low intensity thermal stimulation and finger temperature. Journal of Pain, v.5, n.8, p.458-68, Oct. 2004.

RUSSO, C.M.; BROSE, W.G. Chronic pain. Annual Review of Medicine, v.49, p.123-33, Feb. 1998.

SALT, T.E.; EATON, S.A. Functions of ionotropic and metabotropic glutamate receptors in sensory transmission in the mammalian thalamus. Progress in Neurobiology, v.48, n.1, p.55-72, Jan. 1996.

SHELLEY, A.; CROSS, M.D. Pathophysiology of pain. Mayo Clin. Proc., v. 69, p.375-383, 1994.

SINDRUP, S.H.; JENSEN, T.S. Efficacy of pharmacological treatments of neuropathic pain: an update and effect related to mechanism of drug action. Pain, v.83, n.3, p.389-400, Dec. 1999.

SMITH, G.R.; MONSON, R.A.; RAY, D.C. Patients with multiple unexplained symptoms. Their characteristics, functional health, and health care utilization. Archives of Internal Medicine, v.146, n.1, p.69-72, Jan. 1986.

SULLIVAN, M.J. et al. The treatment of the depression in chronic low back pain: review and recommendations. Pain, v.50, n.1, p.5-13, Jul. 1992.

TEIXEIRA, M. J. Dor e depressão. Revista de Neurociências, v. 14, n.2, p.44-53, 2006.

TEIXEIRA, M.J. Tratamento neurocirúrgico da dor. In: RAIA, A.A.; ZERBINI, E.J. Clínica cirúrgica Alípio Correa Neto. 4.ed. São Paulo: Sarvier, 1988. v.2, cap.62, p.541-72.

TEIXEIRA, M.J.; CORREA, C.F; PIMENTA, C.A.M. Dor: conceitos gerais. São Paulo: Limay, 1994. p.72

TEIXEIRA, M.J.; FIGUEIRÓ, J.A.B. Dor: epidemiologia, fisiopatologia, avaliação, síndromes dolorosas e tratamento. São Paulo: Grupo Editorial Moreira Jr, 2001. 406p.

TERMAN, G.W. et al. Intrinsic mechanisms of pain inhibition: activation by stress. Science, v.226, n.4680, p.231-235, Dec. 1984.

URBAN, M.O.; GEBHART, G. Central mechanism in pain. Medical Clinics of North America, v.83, n.3, p.585-596, May 1999.

VON KNORRING, L. et al. Pain as a symptom in depressive disorders.I.Relationship to diagnostic subgroup and 
depressive symptomatology. Pain, v.15, n.1/4, p.19-26, Jan-Apr. 1983.

WARD, N.G. Pain and depression. In: BONICA, J.J. The Management of pain. 2.ed. Philadelphia: Lea \& Febiger, 1990. p.310-19.

WOOLF, C.J. Pain. Neurobiological Disease, v.7, n.5, p.504-510, Oct. 2000.

WOOLF, C.J.; MANNION, R.J. Neuropathic pain: aetiology, symptoms, mechanisms, and management. The Lancet, v.353, n.9168, p.1959-1964, Jun. 1999.

WÖRTZ, R. Pain - clinical updates - pain depression. Seattle: IASP Press, 1994.
YAARI, Y.; DEVOR, M. Phenytoin suppresses spontaneous ectopic discharge in rat sciatic nerve neuromas. Neuroscience Letters, v.58, n.1, p.117-122, Jul. 1985.

YAKSH, T.L.; MALMBERG, A.B. Central pharmacology of nociceptive transmission. In: WALL, P.D.; MELZACK, R.; BONICA, J.J. Textbook of pain. Edinburgh: Churchill Livingstone, p.165-96, 1994.

YAKSH, T.L.; WILSON, P.R. Spinal serotonin terminal system mediates antinociception. Journal Pharmacology Experimental Therapeutics, v.208, n.3, p.446-53, Mar. 1979.

\section{Sobre os autores}

\section{Edson Lopes da Ponte}

Graduado em Ciências Biológicas pela Universidade Estadual do Ceará (UECE). Atuou como docente, na disciplina de Fisiologia Geral, no curso de graduação em Enfermagem na Universidade Estadual do Ceará, assim como no curso de graduação de Medicina da Faculdade Christus. Atualmente é mestrando em Ciências Fisiológicas UECE onde desenvolve projeto relacionado com produtos naturais sobre a inflamação e a dor no Laboratório de Fisio-farmacologia da Inflamação.

\section{Aline Oliveira Vitor}

Graduada em Ciências Biológicas pela Universidade Estadual do Ceará (UECE). Atualmente é mestranda do Curso de Ciências Fisiológicas da mesma universidade onde atua em pesquisas relacionadas com produtos bioativos provenientes de animais do semi-árido nordestino na dor neuropática no Laboratório de Toxinologia e Farmacologia Molecular. 